\title{
IDENTITY CONSTRUCTION IN CHINESE HERITAGE LANGUAGE CLASSES
}

\author{
Agnes Weiyun He
}

\begin{abstract}
From an interactionally enriched linguistic anthropological perspective, this article promotes the view that identity is indexical with specific sets of acts and stances, which in turn are constructed by specific language forms. Based on detailed sequential and grammatical analyses of data from Chinese heritage language classes, it argues that identity is dynamic, constantly unfolding along with interaction, and thus has the potential to shift and mutate. It positions identity as emerging through co-participants' responses and reactions and thus as an intersubjective and reciprocal entity. It further suggests that identity construction is intricately linked with heritage language learning.
\end{abstract}

Keywords: Language and identity, Classroom discourse, Chinese, Heritage language

\section{Introduction}

The purpose of this article is twofold: To explore the role of interaction in identity construction and to make connections between identity research and Chinese heritage language education. From an interactionally enriched linguistic anthropological perspective, this article promotes the view that identity is indexical with specific sets of acts and stances, which in turn are constructed by specific language forms. It argues that identity is dynamic, constantly unfolding along with interaction, and thus has the potential to shift and mutate. It positions identity as emerging through co-participants' responses and reactions and thus as an intersubjective and reciprocal entity. It further suggests that identity construction is intricately linked with heritage language learning.

\section{Language and identity: A language socialization perspective}

Until not long ago research on the relationship between language and identity has tended to treat the latter as an a priori given and an independent constant that can be invoked to account for variations in language use (for a detailed discussion, see He 1995, 1998; Ochs 1993). More recent constructivist approaches including practice theory (Bourdieu 1977), sociohistorical psychology (Vygotsky 1978), conversation analysis/ethnomethodology (Sacks et al. 1974; Sacks 1992; Atkinson and Heritage 1984; Drew and Heritage 1992; Garfinkel 1967), language acquisition and language socialization (to be specified below), and linguistic anthropology of education (Rampton 1995; Wortham and Rymes 2003) have led researchers to examine identity 
not as a collection of static attributes such as age, occupation, country of birth, skin color, native language, and so forth, but instead as a process of continual emerging and becoming, a process that identifies what a person becomes and achieves through ongoing activities and interactions with other persons and objects.

This paper specifically draws on work from Language Socialization, which, as a branch of linguistic anthropology grounded in ethnography, focuses on the process of becoming a culturally competent member through language use in social activities. As formulated by Ochs and Schieffelin (Ochs 1990, 1996; Ochs and Schieffelin 1984; Schieffelin and Ochs 1986a, 1986b, 1996), Language Socialization is concerned with: (1) how novices (e.g., children, second language learners) are socialized to be competent members in the target culture through language use; and (2) how novices are socialized to use language. It focuses on the language used by and to novices (e.g., children, second language learners) and the relations between this language use and the larger cultural contexts of communication - local theories and epistemologies concerning social order, local ideologies and practices concerning socializing the novices (e.g., rearing children, teaching students), relationships between the novice and the expert, the specific activities and tasks at hand, and so forth.

Within the framework of Language Socialization, identity as part of sociocultural context is constituted by particular stances and acts which in turn are indexed through linguistic forms (Ochs 1990, 1992, 1993). That is to say, from a Language Socialization perspective, the indexical relationship between linguistic forms and language user's identity is often achieved indirectly. According to Language Socialization, "[a] feature of the communicative event is evoked indirectly through the indexing of some other feature of the communicative event. ... [T] he feature of the communicative event directly indexed is conventionally linked to and helps to constitute some second feature of the communicative event, such that the indexing of one evokes or indexes the other" (Ochs 1990: 295). Further, it is not random that some features of the communicative event bear a direct or indirect relationship to linguistic forms. Social identities of the participants are one of the major sociocultural dimensions along with relationships among participants, affective dispositions of participants (feelings, moods, and attitudes of participants toward some proposition), epistemological dispositions of participants (beliefs or knowledge vis-à-vis some proposition, e.g., the source of their knowledge or the degree of certainty of their knowledge), social/speech acts and activities, and genre. Ochs $(1990,1992)$ argues that among these dimensions affective and epistemological dispositions are the two contextual dimensions which are recurrently used to constitute other contextual dimensions. Hence this two-step indexical relationship can be illustrated in Figure 1:

Figure 1. Indexical relationship between language and sociocultural context

$$
\text { linguistic forms } \rightarrow \text { affect/stance } \rightarrow \text { contextual features (identity, activity) }
$$

Language Socialization provides a systematic account of how language relates to identity. It enables us to examine how different displays of and reactions to certain acts and stances construct different identities and relationships. It also allows us to examine the construction of multiple yet compatible/congruent identities, blended and blurred identities in multilingual, multicultural, immigrant contexts (He 1997, 2000, 2003). 


\section{The role of interaction in identity construction}

It has been argued, however, that, while it is feasible to directly link some linguistic features with some affective or epistemological dispositions (the first step in the indexical relationship in the Language Socialization model), it appears more challenging to grasp the constitutive relationship between affective or epistemological stances and other contextual features such as social identities and interpersonal relationships (the second step in the Language Socialization model) (He 2003). In other words, how can we ascertain that it is one specific cultural and situational context (e.g., the participant being a female) and not any other (e.g., the same participant being a teacher) that is invoked by certain affective and epistemological dispositions? To address this concern, we need to ground identity in the interactional production of acts and stances.

While many researchers may agree that social identities come to be created through language (see Bucholtz and Hall 2004, for a thorough discussion), few have explicitly acknowledged the role of interaction. Here I would like to highlight and reinforce the dialogical, interactional perspective within Language Socialization theory and complement it with analytical tools from a parallel perspective, Conversation Analysis (hereafter CA). I suggest that CA may enrich Language Socialization's perspective on identity construction in three different ways. First, CA offers an emergent account of language use and language user, which locates identity work in the context of moment-by-moment interaction. Secondly, CA directly addresses the problem of identity construction through research on "membership categorization." Lastly, CA provides rigorous analytical tools to examine the procedures or interactional devices used by the participants to construct identity. One of these devices is "repair organization" which will be the focal point in our data analysis.

\subsection{CA's notion of emergence}

From a CA perspective, the encounter between any two parties is first and foremost an activity in which the participants try to make sense of what each other is saying. In other words, the participants take it to be a constant objective to achieve a shared understanding of what each other means. Language learning problems and solutions, for example, become problems and solutions when students and teachers together identify and articulate them as such. Interpersonal and cultural knowledge is revealed and reconstructed from the encounter as interaction between the participants unfolds. The participants' understanding of what each other means is dialogically based, in the sense that meaning is jointly constructed through interaction between both parties. Such joint construction of meaning is neither objective nor subjective, but intersubjective. It transcends the polarity between an objectivism which prescribes that there exists some permanent, ahistorical, independent meaning and an anything-goes relativism. The goal of the participants is not to work toward an absolute objectivity but toward an intersubjectivity which is achieved through and mediated by interaction (He 1998).

By interaction, we refer to not only what the participants say to each other in terms of their words (lexicon) and sentence patterns (grammar), or lexicogrammar, but also (and perhaps more importantly) the speech exchange system which regulates who 
speaks when and for how long and related matters. In any interaction, two or more parties (e.g., teacher and students), through talking to each other, influence each other and react to each other, affectively and cognitively. As interaction, these activities take on an emergent quality as the participants jointly build their discourse moment-bymoment. Interaction is a vehicle via which intersubjectivity is constantly built and rebuilt, with the potential of shifting from moment to moment. Reciprocally, intersubjectivity provides the basis for interaction; each speaking turn or turnconstructional-unit is oriented to intersubjectivity established thus far.

By considering identity construction as an interactional achievement, we are able to link language forms and cultural/societal values and preferences, thereby substantiating and operationalizing Language Socialization's theory of indexicality and identity with CAinformed analyses of interactional processes. What this means for Language Socialization research on identity is that in actual analyses of language use, we need to examine how an intersubjective orientation to contexts (including identity) and other realities is established, maintained, or altered moment by moment. We need to focus on how the participants themselves orient to, manage and sustain identity in actual, real-time interaction. The specification of identity as part of the context needs to be derived from orientations exhibited by the participants themselves (Schegloff 1992). Hence for example, in order to claim that some participant's identity as a teacher shapes the way in which language is used, the relevance of that identity must be shown to inhabit the details of the interaction in which the participant takes part.

\section{2. "Membership categorization"}

The body of research from CA that directly addresses the problem of identity construction can be found in Sacks' work on "membership categorization", i.e., how people do descriptions (Sacks 1992) of participants. Sacks noted that when people use descriptions, they employ categories to label themselves, others, and also objects. These categorizations are "inference-rich" (1992: 40-48) in that when a particular category is used, members of a society rely on their local knowledge of what it means to be labeled with such a category. That is to say, when categories are used and interpreted, participants always tie them to specific characteristics and behaviors which are presumed to be characteristic of the category.

One can thus see that there is a strong parallel between CA's conceptualization of membership categorization and Language Socialization's perspective on identity construction. They both emphasize the process via which participants' membership or identity is established. CA focuses on not "categories" but "categorization"; Language Socialization stresses the process of identifying through affect and stances. Further, they both put forth a two-step inference model with regard to the interpretation of participants' identity/membership. For CA, a specific categorization invokes specific characteristics/behaviors which in turn are tied to a specific membership. For Language Socialization, specific language forms index specific affect and stances which in turn index specific social identities.

Sacks also observed that any feature of a person could be used for membership categorization and that several categories can be applied for the same person (e.g., Chinese, a teacher, a female, a mother). What is of interest is the procedures via which participants select membership categories. Repair organization (Schegloff et al. 1977; 
Schegloff 1979, 1996) is just one such membership categorization device, to which I turn next.

\section{3. Repair organization}

While all grammatical, lexical, syntactic and interactional structures can potentially orient to participants' membership categorization or identity construction, repair organization is a particularly effective interactional mechanism for participants to express the stance of affiliation or disaffiliation with each other and, in so doing, to establish, validate, modify, or resist their belonging to one particular membership over another. In the data analysis section below, I will show that it is through interactional mechanisms such as repair that issues of participant identity are expressed and negotiated on a moment-by-moment basis. But first, let us briefly review some relevant literature on repair.

When trouble such as mishearing, misunderstanding, or misspeaking in conversation occurs, it is often noticed and then corrected, either by the party whose turn contains the source of trouble or by some other party. This sequence of trouble + initiationof-correction + correction is known as a repair trajectory. Repair occurs when one party corrects his or her own talk or that of another party and can be accomplished in a number of ways (Schegloff et al. 1977). Of particular relevance to our data are the following:

- Self-initiated same turn repair refers to the situation when the current speaker initiates and completes the repair within his/her current turn of talk before coming to a possible completion of a complete grammatical, lexical, intonational and pragmatic unit, also known as the turn-constructional-unit (TCU) (Ford and Thompson, 1996). It is the earliest position in which repair can be undertaken. The repair is signaled by a number of speech perturbations such as cut-offs, hesitation markers, pauses, and restarts. Schegloff et al. (1977) show that this is the most frequent and the most preferred type of repair.

- Self-initiated repair in transition-relevant-space. If the speaker of the trouble source does not perform repair during the turn in progress, he/she can repair the utterance in the transition-relevant-place, i.e., at the end of a TCU, before another speaker takes a turn.

- Self-initiated third turn repair. In this type of repair (Schegloff 1996), a speaker produces a turn and the hearer responds to it without producing any sign of breakdown in intersubjectivity. After the response by the hearer, the speaker uses the next turn to revise his/her previous turn.

- Self-initiated third-position repair. While in third turn repair the hearer provides an appropriate response which does not prompt repair of the speaker's first turn, in third-position repair (Schegloff 1992) it is precisely the hearer's response that engenders the repair. In other words, the hearer's response enables the speaker to notice a problematic understanding of his/her prior turn.

- Other-initiated self-completed next turn repair is when repair is initiated by a participant other than the speaker of the trouble-source. When this happens, the repair initiation usually comes in the turn immediately subsequent to the troublesource turn (known as next-turn-repair-initiation, or NTRI).

- Other-initiated other-completed repair occurs when a participant other than the speaker of the trouble-source both initiates and completes the repair. It is usually 
preceded by discourse markers such as well or $u \mathrm{hm}$ and often takes the form of a candidate understanding (such as "you mean...") with question intonation. This type of repair can theoretically occur in any turn or any position.

Of the types of repair outlined above, the most preferred repair is self-initiated, selfcompleted, and occurs in the same turn as the trouble-source. Other-initiation and othercompletion of repair can index a stance of disaffiliation; and the farther the distance between the trouble source and the completion of the repair, the greater and longer the miscommunication.

\section{4. Identity work as link between interactional details and contextual concerns}

With an interactionally enriched linguistic anthropological approach to language and identity and analytical tools from Conversation Analysis, we are now able to posit that:

(1) Identity is indexical with specific sets of acts and stances, which in turn are constructed by specific language forms.

(2) Identity is dynamic, constantly unfolding along with interaction, and thus has the potential to shift and mutate.

(3) Identity emerges (at least in part) through others' responses and reactions and as such identity construction is intersubjective and reciprocal; the construction of one participant's identity also simultaneously constructs that of the other.

In what follows, after a brief sketch of the research context, I detail the interactional processes through which the participants' identities come to be constituted, (re-)enacted, modified, negotiated, or rejected. I focus on the language form of various repair trajectories, examine how they index stances of affiliation or disaffiliation among the participants, and link these issues with participants' identity/membership categorization.

\section{Classroom roles/identities: The research context}

Data presented in this paper were collected in two Chinese Heritage Language Schools in two different cities in the U.S., where evening or weekend Chinese language classes are offered for children whose parents come from China or Taiwan and are pursuing professional careers in the U.S. These children were either born in the U.S. or came to the U.S. with their parents at a very young age. Most of them go to mainstream Englishspeaking schools on weekdays. While many of them are bilingual in Chinese and English in the oral form, some are already English-dominant and few have opportunities to learn how to read and write in Chinese. Their parents send them to these Chinese language schools for the children to acquire literacy in the heritage language and to affirm their ethnicity.

As researchers have noted, heritage language schools like these which combine elements from family, community and school, function as an important vehicle for ethnic minority children to acquire heritage language skills and cultural values (Bradunas and Topping 1988; Wang 1996; Peyton et al. 2001). The corpus includes (1) 30 hours of audio and video recorded class meetings involving 4 teachers in 4 different 
classes and a total of 35 children (aged 4.5 to 9), (2) classroom observations, and (3) interviews with parents, teachers and school administrators. Detailed information about the classes can be found in Appendix A.

Although "teacher" and "student" are universal social roles, the communicative practices of teachers or students vary considerably across classrooms, cultures and societies. As argued above, there is not a one-to-one mapping relationship between language forms such as three-phased moralized directives (He 2000) and the social identity of the participant as a Chinese teacher. Instead, the relation of moralized directives to the identity of the Chinese teacher is constituted and mediated by the relation of language forms to stances (e.g., moral and authoritative), activities and other social constructs. As such, students in these classes come to understand teacher-related meanings in part through coming to understand certain recurrently displayed stances (e.g., upholding moral values such as filial piety).

In the context of teaching/learning Chinese as a heritage language, it is possible that teachers or students may fail to achieve identities of "teacher" or "student" through failure to act and feel in some way as expected, desired or preferred by their coparticipants or through the failure of their co-participants to ratify the teachers' or students' displayed acts and stances. Section 4 aims to provide an empirical and interactional account of social identities and interpersonal relationships between the teacher and the students in the Chinese heritage language classroom.

\section{Repair as a resource for identity construction}

\subsection{Expert-novice role relations}

Originating in the teachings of Confucius and Mencius two thousand years ago is the notion of shi dao zun yan - the supremacy of the Way of the teacher. The teacher in a traditional Chinese classroom is someone who is the indisputable, unchallenged center and authority of knowledge. The student accordingly is someone who is expected to listen, observe, and follow the teacher's instructions. Below, in data segment (1), I aim to show that the expert-novice relation between the teacher and the students in Chinese heritage language classes is not a clear-cut case of an instance of "traditional" classroom practice; instead, it may in fact take on a highly emergent quality as the participants ratify, reverse, reject or make irrelevant their prescribed role identities moment-bymoment.

The scenario in (1) concerns the choice of script between jiantizi, the simplified script, which is the official script used in mainland China, and fantizi, the traditional (un-simplified) script, which is typically used in Taiwan and elsewhere. While the heritage language schools I observed adopted textbooks published in mainland China (in jiantizi), they also provided their students with supplementary reading materials published elsewhere such as Taiwan and Hong Kong. As a principle, the schools I observed accept any choice made by the instructor or by students who may prefer one script to the other. In the case of (1) below, the teacher, who received her education in mainland China before moving to Taiwan (and then the U.S.), chooses to use jiantizi. Student G5's family is from Taiwan and prefers fantizi. (Transcription symbols can be found in Appendix B and grammatical gloss in Appendix C.) 
(1) ('Choice of script: Expert-novice relations') [TCCDL:953]

((Tc is walking around to check each individual student's writing.))

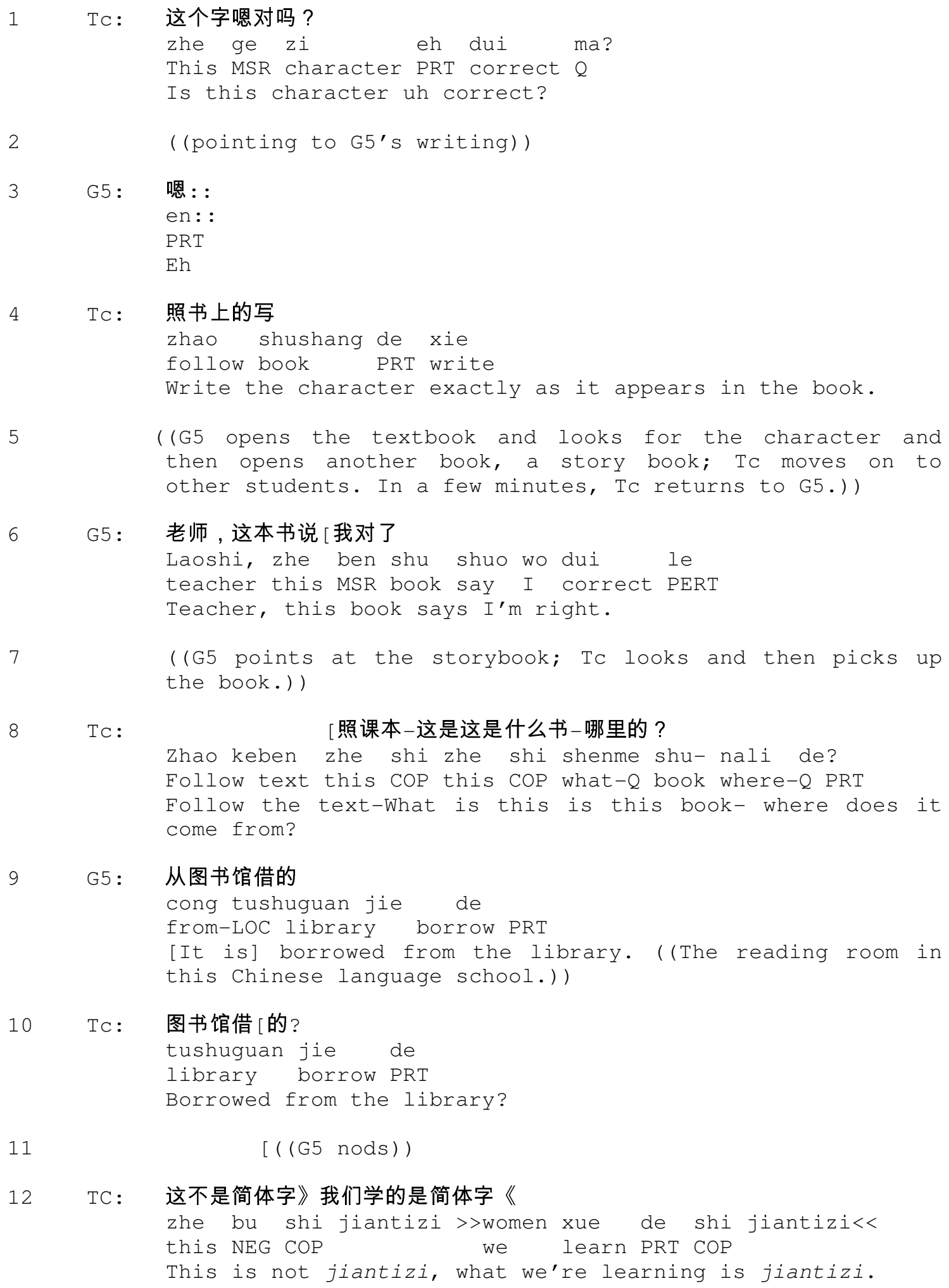

\section{G5： 从图书馆借的}

10 TC： 图书馆借 [的?

12 TC: 这不是简体字》我们学的是简体字《

zhe bu shi jiantizi >>women xue de shi jiantizi<< this NEG COP we learn PRT COP

This is not jiantizi, what we're learning is jiantizi. 
G5：陈老师说学繁体字简体字都 ok

chen laoshi shuo xue fantizi jiantizi dou ok teacher say learn all-EMP ok Teacher Chen says that learning fantizi and jiantizi are both fine.

15 TC: 那-那好。

na na hao.

Then then good.

Then- okay then.

(.2) ((TC puts down the storybook.))

$17 \mathrm{TC}$ ：让我看你写得对吗。

Rang wo kan ni xie de dui ma.

Let I see you write PRT correct $Q$

Let me see whether you wrote it correctly.

( (G5 hands in the storybook to TC; TC checks G5's writing against the storybook.))

19 TC: 好。

hao.

Good.

In terms of sequential organization, Tc (line 1) begins with a question concerning whether a specific character was written correctly, a question to which G5's answer appears uncertain (line 3). Tc then advises G5 to follow the book (line 4). G5 consulted two books, first the textbook and then a storybook (line 5), and finally reported to Tc that the book proved her right (line 6). At this point, realizing that G5 has mistakenly taken her previous turn (line 4) to mean "follow any book", Tc initiates and completes a third position repair ("follow the textbook", line 8) of her turn in line 4. Immediately subsequent to the third position repair, Tc also completes a self-initiated same turn repair (marked by cut-offs, restarts, line 8), shifting the focus from the specification of which book G5 should consult to the questioning of the origin of the storybook. After G5's reply that the book is from the school reading room (line 9), Tc provides a next turn repair initiation (NTRI) with a partial repeat of G5's previous turn, casting disbelief and doubt concerning the legitimacy of the book (line 10). G5, however, affirms that the book is indeed from the school reading room (line 11); in other words, the NTRI from Tc in line 10 did not succeed in getting G5 to complete any repair of her (G5's) previous turn in line 9. Tc subsequently states that the character form present in the storybook is not permissible (line 12), to which G5 counters by invoking the school principal (line 13). Tc then reluctantly (indicated by the cut-off) gives in and revises her assessment of the book (line 14). Finally, Tc asks to check G5's writing (line 17), a request with which G5 complies (line 18). Tc ends with an evaluation of G5's writing (line 19).

A schematic representation of the sequential organization follows:

- Tc: question (line 1) $\rightarrow$ G5: answer (line 3) 
- Tc: directive (line 4) $\rightarrow$ G5: response to directive (line 6) $\rightarrow$ Tc: third position repair (line 8)

- Tc: question (line 8) $\rightarrow$ G5: Answer (line 9) $\rightarrow$ Tc: next turn repair initiation (line $10) \rightarrow$ G5: no repair (line 11)

- Tc: assessment (line 12) $\rightarrow$ G5: counter assessment (line 13) $\rightarrow$ Tc: revised assessment (line 14)

- Tc: directive (line 17) $\rightarrow$ G5: compliance (line 18) $\rightarrow$ Tc: evaluation (line 19)

By attending to interactional details moment by moment, we are able to see that the teacher's expertness and authority is not presupposed to the same degree at all times and is not readily accepted by the student at all times. In this segment, the teacher began being the expert/authority by asking a question (line 1) and issuing a directive (line 4). The student's response to the directive (line 6), however, compelled the teacher to respecify her original directive (line 8). Subsequently, the expert-novice relationship became neutralized, if not reversed. The teacher was not knowledgeable about the origin of the storybook (line 8), whereas the student was (line 9). When the teacher further challenged the student (line 10), the student did not revise her statement (line 11). The student was finally able to strike a balance in the interpersonal relationship when she countered (line 13) the teacher's assessment (line 12) and succeeded in making the teacher agree with her (line 14). In the end, the expert-novice relationship returned to what it was like in the beginning of this episode: the act of examining (line 17) and evaluating (line 19) the student's character writing (though in fantizi) and the student's compliance (line 18) re-established the teacher's expert position. In other words, if the stance of expertness and authority indexes the identity of the teacher, here the expert and authority status is not a static property, but instead an emergent one and the expertnovice relationship is constantly shifting as the interaction unfolds.

\section{2. Multiple, shifting group/cultural identities}

To examine participants' cultural identity is always a complex inferential and social process. From a Language Socialization perspective, this is because our understandings of which acts and stances constitute resources for constructing particular cultural identities are limited. However, group and cultural identities are particularly relevant and salient in heritage language education. Unlike the case of foreign/second language learning where the learner is clearly a member of his/her "native culture" who is attempting to learn the norms and rules of the "target culture" as enacted and (re)constituted by the target language he/she is learning, the learner of a heritage language appears to have a multi-faceted identity as someone who is both similar to and different from members of the target culture since he/she is socio-historically connected with the target culture and yet experientially displaced from it. Through data excerpt (2), we may be able to see that with varying language forms - personal pronouns and shifting lexical entailments in various repair trajectories - the students and the teacher present themselves differently and project differential interpersonal alignments with regard to cultural/institutional groups.

(2) ('Who are "we"?: Multiple, shifting learner identities') [TCCDL:953] 
((Tc is organizing the class to set up a writing contest between two groups. women 'we'; nimen 'you'; tamen 'they'))

1 TC: 好 (。2) 我们现在分成两个组 $=$

hao (.2) women xianzai fen cheng liang ge zu= Good we now divide PERT two MSR group Ok now let's break into two groups.

2 B3: =我们比赛 ? !

=women bisai?!

We compete

We're going to have a contest?!

3 Ss: $\quad[$ Yeah : :

4 TC：［比赛 (。) 对 (。) 看哪组又快又好

[bisai (.) dui (.) kan na zu you kuai you hao compete yes see which-Q group CONJ fast CONJ good

Yes, competition. See which group is both faster and better.

5 G4: 谁-谁谁输谁就买 cookies yeh: :

sh- shui shui shu shui jiu mai cookies yeh: who-Q who lose who CONJ buy

Whoever loses buys cookies (for everybody)

Tc: 买 cookie? 我们学习啊不用吃的

mai cookie? Women xuexi ah bu yong chi de

buy we learn PRT NEG use eat POS

Buy cookies? We are here to learn. We don't need food.

((Pause. Students moving seats to get into groups.))

8 G4: 在学校Mrs. Colon (.2) 叫我们这样

zai xuexiao Mrs. Colon jiao women zhe yang

at school ask us this manner

At school Mrs. Colon asks us to do like this.

9 Tc：这里-这里嗯是中文学校啊我们不一

zheli- zheli uh shi zhongwen xuexiao ah women buhere PRT COP Chinese school PRT we NEG It's it's uh Chinese school here. We don't-

\section{他们这样我们不这样啊}

tamen zhe yang women bu zhe yang ah they this manner we NEG this manner PRT They do this (but) we don't.

( (In the subsequent 2-3 minutes, the two groups are well into the contest. Tc is looking for the next word.))

12 B?: 老师我们赢了有 extra credit 吗?

laoshi women ying le you extra credit ma?

Teacher we win PERT have

Teacher if we win do we get extra credit? 
13

14

$(.4)$

\section{B3：我们赢了就加分。}

women ying le jiu jia fen.

We win PERT CONJ add point

We should receive extra points if (we) win.

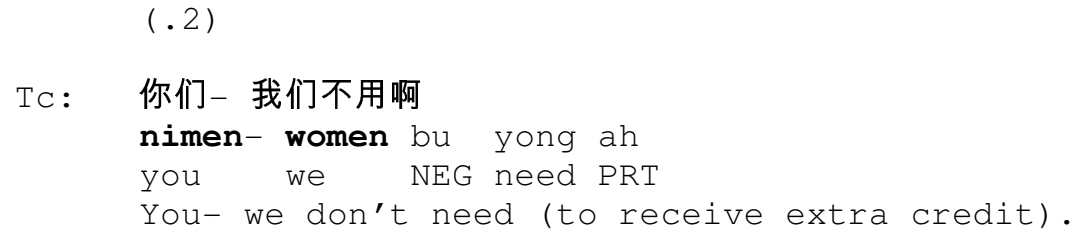

( (A parent entered the classroom to pick up her child early and the discussion on whether the writing contest should be associated with rewards is interrupted and never picked up again in this class meeting.))

The table below summarizes the use of different pronouns by different speakers. CLS stands for Chinese Language School; DTS refers to the regular daytime school the students attend during weekdays.

Table 1. References in data extract (2)

\begin{tabular}{|l|l|l|l|}
\hline Line \# & Speaker & Pronoun: referent & Activity \\
\hline \hline 1 & Tc & we: Ss at CLS & have a writing contest \\
\hline \hline 2 & B3 & we: Ss at CLS & have a writing contest \\
\hline 6 & Tc & we: Ss at CLS & don't need food when learning \\
\hline \hline 8 & G4 & we: Ss at DTS & have cookies as learning rewards \\
\hline \hline 9 & Tc & we: Ss and T at CLS & don't need food/rewards \\
\hline \hline 10 & Tc & they: Ss and T at DTS & have/allow cookies as rewards \\
\hline 10 & Tc & we: Ss and T at CLS & don't need/allow food/rewards \\
\hline
\end{tabular}




\begin{tabular}{|l|l|l|l|}
\hline 12 & B? & we: Ss at CLS & get extra points? \\
\hline \hline 14 & B3 & we: Ss at CLS & should get extra points \\
\hline \hline 16 & Tc & we: Ss at CLS & don't need extra points \\
\hline \hline 17 & Tc & they: T at DTS & give extra points? \\
\hline \hline 19 & Tc & we: Ss at CLS & don't need cookies or points \\
\hline \hline 20 & B3 & we: Ss at DTS & get extra points \\
\hline \hline 21 & B3 & we: Ss at DTS & get extra points \\
\hline
\end{tabular}

If we focus on each of the pronouns, women 'we' is used to refer to (1) students at CLS (by both Ss and Tc), (2) students and teachers at CLS (by Tc), (3) students at daytime schools (by Ss), and (4) all students at daytime schools (by Ss). Nimen 'you' is used by Tc to refer to students at CLS (line 16). And tamen 'they' is used by Tc to refer to (1) students and teachers at daytime schools and (2) teachers at daytime schools (lines 10 and 17). Alternatively, if we focus on each of the speakers, the students are selfpresented as (1) students at CLS, (2) students at daytime schools, and (3) members of the entire student body at daytime schools. The students are other-presented by Tc as members of CLS only. In other words, while students identify themselves with daytime schools as well as with CLS using women 'we' in all cases, Tc clearly differentiates CLS from daytime schools, marking in each case students and teachers at daytime schools as tamen 'they'.

This data segment is also characterized by a number of repair sequences. In line 5, G4 completes a self-initiated same turn repair, announcing that whichever team loses the contest will need to buy cookies for everyone. This turn is marked by perturbations in the beginning and the mid-turn code switch from Chinese to English. In line 6, Tc extends an other-initiated other-completed repair. She first offers a repair initiation through a partial repeat of G4's previous turn with a question intonation ("Buy cookies?"), which structurally could have functioned as a next turn repair initiation. However, without allowing any space for G4 to respond to the repair initiation, Tc continues to complete the repair herself within the same speaking turn, stating that learning should not be associated with food. Hence interestingly enough, on the one hand, Tc appropriates the English item introduced by G4 ("cookie"), thereby exhibiting her own identification with the students' linguistic membership categorization (i.e., bilingual in Chinese and English). On the other hand, she opts to use the least affiliative repair strategy, that of other-initiated, other-completed repair.

In line 8, G4 argues for the legitimacy of buying cookies by invoking the practices of her daytime school. In lines 9-10, Tc strives (as evidenced by cut-offs and hesitations in the beginning of the turn) to present a counter argument by differentiating Chinese Language School from daytime school. There are two instances of self-initiated same turn repair in lines 9-10. The first occurs at the beginning of the turn when Tc is trying to justify why buying cookies is not appropriate. The second instance occurs when she contrasts what is acceptable in CLS with what is acceptable in DTS ("we" versus "they").

In line 16, in reply to a student's question (line 12) whether the winning team will get extra points, Tc produced another self-initiated same turn repair (from "you" to "we"), this time shifting from a categorization of students and herself as separate entities to an identification of students and herself as belonging to the same membership. 
The last instance of repair occurs in line 19. It is yet another self-initiated same turn repair. Unlike other instances of repair of the same type, however, in this instance, the repair is completed through code-switching from Chinese to English at the end of a turn-constructional-unit ("We don't need it"). As Tc clearly spoke Chinese much better than English and since she rarely used English in the classroom, code-switching in this case can be seen as evidence for identity adjustment (Martin-Jones, 1998) for Tc, an adjustment from someone who makes a clear distinction between the Chinese speaking "we" and the English speaking "they" to someone who is receptive to ambivalence, duality and possibly change.

Table 2 considers areas where the usage of personal pronouns and sequential organization of this spate of talk converge. It locates the personal pronouns in the trouble source-repair initiation-repair completion sequence.

Table 2. Pronouns and repair sequence in data segment (2)

\begin{tabular}{|l|l|l|l|}
\hline Line \# & Speaker & Pronominal reference & Location of reference in repair sequence \\
\hline \hline 6 & Tc & $\begin{array}{l}\text { ("buy cookie") } \\
\text { we }\end{array}$ & $\begin{array}{l}\text { (trouble source) } \\
\text { other repair }\end{array}$ \\
\hline \hline 9 & Tc & $\begin{array}{l}\text { we } \\
\text { they }\end{array}$ & $\begin{array}{l}\text { trouble source } \\
\text { self-repair }\end{array}$ \\
\hline \hline 16 & Tc & $\begin{array}{l}\text { you } \\
\text { we }\end{array}$ & $\begin{array}{l}\text { trouble source } \\
\text { self-repair }\end{array}$ \\
\hline \hline 19 & Tc & $\begin{array}{l}\text { we } \\
\text { (code-switch) }\end{array}$ & $\begin{array}{l}\text { trouble source } \\
\text { (self-repair) }\end{array}$ \\
\hline
\end{tabular}

Table 2 shows that where personal references and repair sequences converge, the speaker is exclusively the teacher. As specified above, in each of these instances and accumulatively, the teacher attempts to categorize the students as members of CLSs (as opposed to DTSs) and to align herself with the students.

To sum up, the students' self-presentation appears to be multi-faceted and fluid; they categorize themselves as members of simultaneously-existing multiple groups and move in and out of groups with ease, aligning themselves with CLS, their daytime school and/or their teacher at various points in time. The teacher, on the other hand, appears to make every effort (including a succession of self-initiated repairs) to categorize the students solely as members of CLS. In other words, as the participants collaboratively (although differently) define the identity of the students, they at the same time also jointly re-create the identity of the teacher.

\section{Concluding remarks}

In this paper, I have considered how an interactionally enriched Language Socialization perspective may shed light on the construction of identities in the context of Chinese heritage language classes. I have focused on repair sequences in teacher-student interactions as specific language forms which construct various affective stances of certainty or uncertainty, knowledgeablity or unknowledgeablity, affiliation or disaffiliation which in turn are constitutive of participant identities of expert/novice, teacher/students, CLS/DTS students, Chinese or American or Chinese American. 
Much remains to be investigated in future studies in terms of the relationship between interaction, identity, and heritage language learning. To learn one's heritage language is in part to (re)establish similarities with members of one's heritage culture or to (re)establish differences from members of mainstream American culture. Theoretically, which acts and stances are constitutive of the shift of learners' (and teacher's) identities that necessarily accompanies and potentially enables language learning? On what grounds could we build a strong connection between change in interactional trajectory, change in acts/stances and thus identity, and change in language ability? Empirically, the robustness of the notion of identity as brought about through interaction needs to be evaluated against the background of classic research on the ethnography of communication (e.g., Gumperz and Cook-Gumperz 1982). On the other hand, as fundamental notions such as "speech community" may be in need of further definition in the light of postmodern identity dynamics, contexts such as that of heritage language learning provide possibilities for us to re-examine these notions empirically.

\section{References}

Atkinson, J.M., and J. Heritage (eds.) (1984) Structures of social action: Studies in conversation analysis. Cambridge: Cambridge University Press.

Bucholtz, M., and K. Hall (2004) Language and identity. To appear in A. Duranti (ed.), Companion to linguistic anthropology. Malden, MA: Blackwell, pp. 369-394.

Bourdieu, P. (1977) Outline of a theory of practice. R. Nice (Trans.). Cambridge: Cambridge University Press.

Bradunas, E., and B. Topping (eds.) (1988) Ethnic heritage and language schools in America. Washington, DC: Library of Congress.

Drew, P., and J. Heritage (eds.) (1992) Talk at work. New York: Cambridge University Press.

Ford, C., and S. Thompson (1996) Interactional units in conversation: Syntactic, intonational, and pragmatic resources for the management of turns. In E. Ochs, E. Schegloff, and S. Thompson (eds.), Interaction and grammar. Cambridge: Cambridge University Press, pp. 52-134.

Garfinkel, H. (1967) Studies in ethnomethodology. Englewood Cliffs, NJ: Prentice-Hall.

Gumperz, J.J., and J. Cook-Gumperz (1982) Language and the communication of social identity. In J.J. Gumperz (ed.), Language and social identity. Cambridge: Cambridge University Press, pp. 1-21.

He, A.W. (1995) Co-constructing institutional identities: The case of student counselees. Research on Language and Social Interaction 28.3: 213-231.

He, A.W. (1997) Learning and being: Identity construction in the classroom. Pragmatics and Language Learning 8: 201-222.

He, A.W. (1998) Reconstructing institutions: Language use in academic counseling encounters. Greenwich, CT and London, UK: Greenwood.

He, A.W. (2000) Grammatical and sequential organization of teachers' directives. Linguistics and Education 11.2: 119-140. 


\section{Agnes Weiyun He}

He, A.W. (2003) Linguistic anthropology and language education. In S. Wortham and B. Rymes (eds.), Linguistic anthropology of education. Westport, CT and London: Praeger, pp. 93-119.

Martin-Jones, M. (1998) Teaching and learning bilingually: A survey of recent research. Working Papers in Urban Language and Literacies, Kings College, London. Available at http://www.kcl.ac.uk/depsta/education/ULL/WP10MMJ.doc.pdf.

Ochs, E. (1990) Indexicality and socialization. In J.W. Stigler, R. Shweder, and G. Herdt (eds.), Cultural psychology: Essays on comparative human development. Cambridge: Cambridge University Press, pp. 287-308.

Ochs, E. (1992) Indexing gender. In A. Duranti and C. Goodwin (eds.), Rethinking context. New York: Cambridge University Press, pp. 335-358.

Ochs, E. (1993) Constructing social identity. Research on Language and Social Interaction 26: 287-306.

Ochs, E. (1996) Linguistic resources for socializing humanity. In J.J. Gumperz and S.L. Levinson (eds.), Rethinking linguistic relativity. Cambridge University Press, pp. 407-437.

Ochs, E., and B. Schieffelin (1984) Language acquisition and socialization: Three developmental stories. In R. Schweder and R. LeVine (eds.), Culture theory: Essays on mind, self and emotion. Cambridge: Cambridge University Press, pp. 276-320.

Peyton, J.K., D.A. Ranard, and S. McGinnis (eds.) (2001) Heritage languages in America: Preserving a national resource. McHenry, IL: Delta Systems Co, Inc.

Rampton, B. (1995) Crossing: Language and ethnicity among adolescents. London: Longman.

Sacks, H. (1992). Lctures on conversation. (volumes 1 and 2.) Blackwell.

Sacks, H., E.A. Schegloff, and G. Jefferson (1974) A simplest systematics for the organization of turntaking for conversation. Language 50: 696-735.

Schegloff, E.A. (1979) The relevance of repair to syntax-for-conversation. Syntax and semantics 12: 261286.

Schegloff, E.A. (1992) Repair after next turn: The last structurally provided place for the defense of intersubjectivity in conversation. American Journal of Sociology 95/5: 1295-1345.

Schegloff, E.A. (1996) Third turn repair. In G.R. Guy, C. Feagin, D. Schiffrin, and J. Baugh (eds.), Towards a social science of language. Papers in honors of William Labov, vol 2: Social interaction and discourse structures. Amsterdam: John Benjamins, pp. 31-40.

Schegloff, E.A., G. Jefferson, and H. Sacks (1977) The preference for self-repair in the organization of repair in conversation. Language 53: 361-382.

Schieffelin, B., and E. Ochs (eds.) (1986a) Language socialization across cultures. New York: Cambridge University Press.

Schieffelin, B., and E. Ochs (1986b) Language socialization. Annual Review of Anthropology 15: 163191.

Schieffelin, B., and E. Ochs (1996) The microgenesis of competence. In D. Slobin, J. Gerhardt, A. Kyratzis, and J. Guo (eds.), Social interaction, social context, and language. Mahwah, NJ: Lawrence Erlbaum, pp. 251-264.

Vygotsky, L. (1978) Thought and language. Cambridge, MASS: MIT Press. 
Wang, X. (ed.) (1996) A view from within: A case study of Chinese heritage community language schools in the U.S. Washington, DC: National Foreign Language Center.

Wortham, S., and B. Rymes (eds.) (2003) Linguistic anthropology of education. Westport, CT and London: Praeger.

\section{Appendix A. The four classrooms}

\section{Classroom 1}

This was a higher-middle level (bin ban) class in a range of four proficiency level classes offered in City A, a metropolitan city in southeast U.S. The students consisted of 4 girls and 9 boys, aged between $41 / 2$ and 8 . Classes met from 1:30pm to 3:30pm (with a 10 minute break at 2:30), on Sundays, on the top (18th) floor of a university apartment building. A total of 10 hours of lessons in this setting were audio taped.

The instructor was Teacher Wang (Tw), a 45 year old female with a bachelor's degree from China in philosophy. Prior to coming to the U.S., she had taught in elementary schools, middle schools as well as universities in Beijing and its vicinities. She spoke little English.

\section{Classroom 2}

Eight hours of class meetings provided the database for Classroom 2, which was beginning level Chinese, the lowest of the three levels (xiao ban) offered in City C, a university town in mid-west U.S. There were 1 girl and 2 boys in this class, aged between 5 and 6 . Classes met from 6:15pm to 7:50pm on Tuesdays, on the university campus.

Teacher Zhang $(\mathrm{Tz})$, the instructor, was a 33 year old female, who had recently received a master's degree in educational psychology in China, where she had taught adult students. She was frustrated by the lack of appropriate textbooks for overseas Chinese children and was very interested in learning (new) ways of teaching children.

\section{Classroom 3}

Six hours of video- and audio-recorded class meetings provided the database for Classroom 3, which was intermediate level Chinese, the middle of the three levels (zhong ban) offered in the same school as Classroom 2. There were 5 girls and 2 boys in this class, aged between 5 and 9 . Classes met at the same time in the same building as Classroom 2.

Teacher Shen (Ts), the instructor, was a 27 year old female, a native of Taiwan, who had recently received a master's degree in accounting in the U.S. She had been teaching in this capacity for two years.

\section{Classroom 4}

Six hours of video- and audio-recorded class meetings provided the database for Classroom 4, which was advanced level Chinese, the highest of the three levels (da ban) offered in the same setting as Classrooms 2 and 3. There were 8 girls and 4-5 boys in this class, aged between 5 and 9. Classes met at the same time in the same building as Classrooms 2 and 3.

Teacher Chao (Tc), the instructor, was a 28 year old female, a native of Taiwan, who had been in the U.S. for 6 years and was taking some computer courses at a local community college. She had experience teaching in a similar Chinese language school in another state and had been teaching in this particular school for 2 months. 


\section{Appendix B. Transcription symbols}

CAPS emphasis, signaled by pitch or volume

falling intonation

falling-rising intonation

quiet speech

[ ] overlapped talk

- cut-off

$=\quad$ latched talk

: $\quad$ prolonged sound or syllable

(0.0) silences roughly in seconds and tenths of seconds (measured more according to the relative speech rate of the interaction than to the actual clock time)

(.) short, untimed pauses of one tenth of a second or less

( ) undecipherable or doubtful hearing

(( )) additional observation

$\mathrm{T}$ : at the beginning of a stretch of talk, identifies the speaker; $\mathrm{T}$ is for teacher (different teachers are represented by different small letters such as Ts or Tz), G for girl, B for boy, Ss for whole class.

$\rightarrow \quad$ speaking turns of analytical focus

$<>\quad$ slow speech

$>\quad$ fast speech

\section{Appendix C. Grammatical gloss}

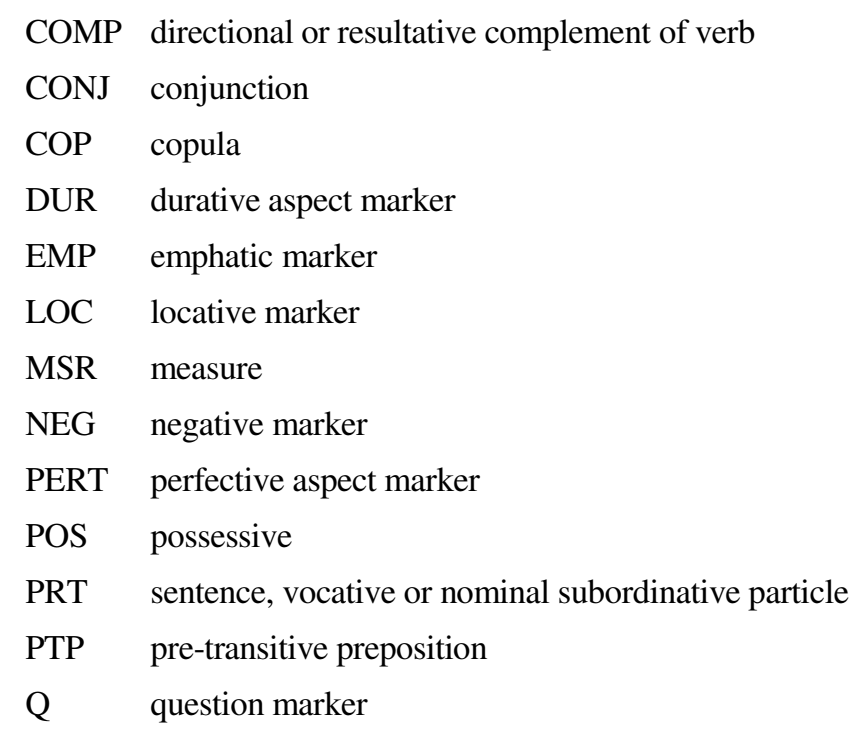

